International Journal of Arts and Humanities

ISSN: 2581-3102

Volume: 04, Issue: 01 "January 2020"

\title{
A SOCIO-ECONOMIC ASSESSMENT OF PRADHAN MANTRI UJJWALA YOJANA
}

\author{
Yashi Yadav \\ Student at The Don Bosco Senior Secondary School, Gorakhpur.
}

\begin{abstract}
We wanted to assess the social and economic aspect of Pradhan Mantri Ujjwala yojana in detail The Scheme proved to be a milestone in the Indian Economy. The Central government's initiative to provide free LPG connections has been in operation for more than 3 years providing more than 7 crores LPG connections. The scheme is all about providing free LPG connection to the women who belongs to the poor families. In this paper we have discussed and explained the impact of this yojana. 80 million poor families are the beneficiaries of this yojana.
\end{abstract}

Keywords: LPG Connection, Yojana, Social, Economic, Financial Support.

Abbreviations: PMUY = Pradhan Mantri Ujjwala Yojana, $\mathrm{LPG}=$ Liquid Petroleum Gas, $\mathrm{OMC}=$ Oil Marketing Companies, IOCL= Indian Oil Corporation Ltd, BPCL= Bharat Petroleum Company Ltd, HPCL= Hindustan Petroleum Company Ltd.

\section{INTRODUCTION}

Each year in India, immoderate indoor air pollution claims over 120,000 lives[2]. The Pradhan Mantri Ujjwala Yojana was introduced on 1 May 2016 by Prime Minister of India Narendra Modi to provide 8 crores LPG connections to poor women by March 2019 without any cost. As of now more than 7 crores LPG connections have been provided.

Under the scheme, the government aims to provide cooking gas to poor households[7]. The scheme aims to replace cooking fuels used mostly in rural India with clean liquefied petroleum gas (LPG).The scheme allows the government to provide cooking gas connections to poor women along with financial assistance over a period of three years. Eligible families are identified through the Socio-Economic Caste Census 2011 data[8]. Ujjwala scheme provides financial support of Rs1,600 for each cooking gas connection to eligible households. The connections are given in the name of the women heads of households. The government also provides an equated 
International Journal of Arts and Humanities

ISSN: 2581-3102

Volume: 04, Issue: 01 "January 2020"

monthly instalment facility for meeting the cost of stove and refills[1]. The government allocated a sum of INR 80 billion to the project to support the subsidy of INR 1,600 per connection for providing 50 million LPG connections to BPL (Below the Poverty Line) families over a period of three years, from 2016-2019.The target for beneficiaries was subsequently increased to 80 million BPL families by the year 2019-20. The task of providing the connections was entrusted to three government-owned Oil Marketing Companies (OMCs),

1. Indian Oil Corporation Ltd. (IOCL)

2. Bharat Petroleum Company Ltd. (BPCL) and

3. Hindustan Petroleum Company Ltd. (HPCL).

The vast scale and scope of the project required meticulous planning and execution. PMUY is a remarkable example of redistribution of fuel subsidy savings that have been realized through policy reforms. Over the past four years (2014-18) the Government of India (GOI) launched the direct benefit transfer in LPG subsidy (DBTL), followed by the "Give-it-up" campaign, during which time the government nudged wealthy customers to surrender their LPG subsidy. These initiatives resulted in the removal of approximately 38 million "ghost" or "fake" beneficiaries from the system and the voluntary surrender of fuel subsidies by more than 10 million affluent beneficiaries respectively. By launching PMUY, the GOI redistributed the savings of USD 6.3 billion (though this amount is often disputed in the public domain) to poor people who live in rural areas without clean cooking gas.

\section{RELATED WORK}

Dr. Mamta Sharma Pareek [1] proposed an article which is basically an analysis of Pradhan Mantri Ujjwala Yojana, in that article she explained almost each and every aspect of PMUY including the strategy behind it, the evaluation of the scheme, benefits, challenges and suggestions like to realize the true benefits of the scheme the government must build proper mechanism to identify the deserving beneficiaries.

Samir Kumar Barua and Sobhesh Kumar Agarwallal[3] published an article in IIMA and narrated the story of a vital attempt to transform the social life of poor people by providing the cooking gas (LPG) at a very marginal cost. They discussed a very important angle of government, how it provides subsidies on some petroleum products.

Ashwani Dabadge, Ashok Sreenivas and Ann Josey published an article about Pradhan Mantri Ujjwala Yojana: What We Need to Know in the Economics Times in 2018[4]. Basically, it was an assessment of the yojana, how it went and made a big mark on Indian Society. The Article 
International Journal of Arts and Humanities

ISSN: 2581-3102

Volume: 04, Issue: 01 "January 2020"

showed some survey on the LPG connections in the country before and after the launch of PMUY.

Yashi Yadav [5] has explained the socio-economic aspect of the Pradhan Mantri Ujjwala Yojana by keeping some very crucial points in mind and tried to explain some untouched aspect of the Yojana by using some data.

\section{RESEARCH METHODOLOGY}

The research is informative and explanatory in nature where empirical study has been made about the poor, backward and marginalized society, their economic and social inclusion by government plan and schemes. Attempt has been made to present a clarification on the understanding and working of Pradhan Mantri Ujjwala Yojana (PMUY). The researcher has relied on the reports, news and various survey for descriptive analysis.

\section{EXPLANATION AND ANALYSIS}

\section{Social Incorporation}

Social incorporation [5] is something which is very different to Social exclusion. The individual or groups of individuals who are socially excluded do not allow themselves to wholly participate in economy, social life and political life of the nation. This lessen unity, increases social tension and turns down the economic progress of the country. People are born in the complex web of social and economic level of the society, which determine their assets endowment, behavior and thinking pattern. This is due to these situations or habits or s some people or group of people remained outside the mainstream of the Society and slowly became poor, backward and downtrodden. Social inclusion is a process, which seeks to bring about the reforms or policy changes to reduce inequities in access to assets, capabilities and opportunities. It is about giving concessions, incentives to marginalize or socially excluded group of people to develop capacity and empowerment to enable them to actively participate in social and economic development of the country. 
International Journal of Arts and Humanities

ISSN: 2581-3102

Volume: 04, Issue: 01 "January 2020"

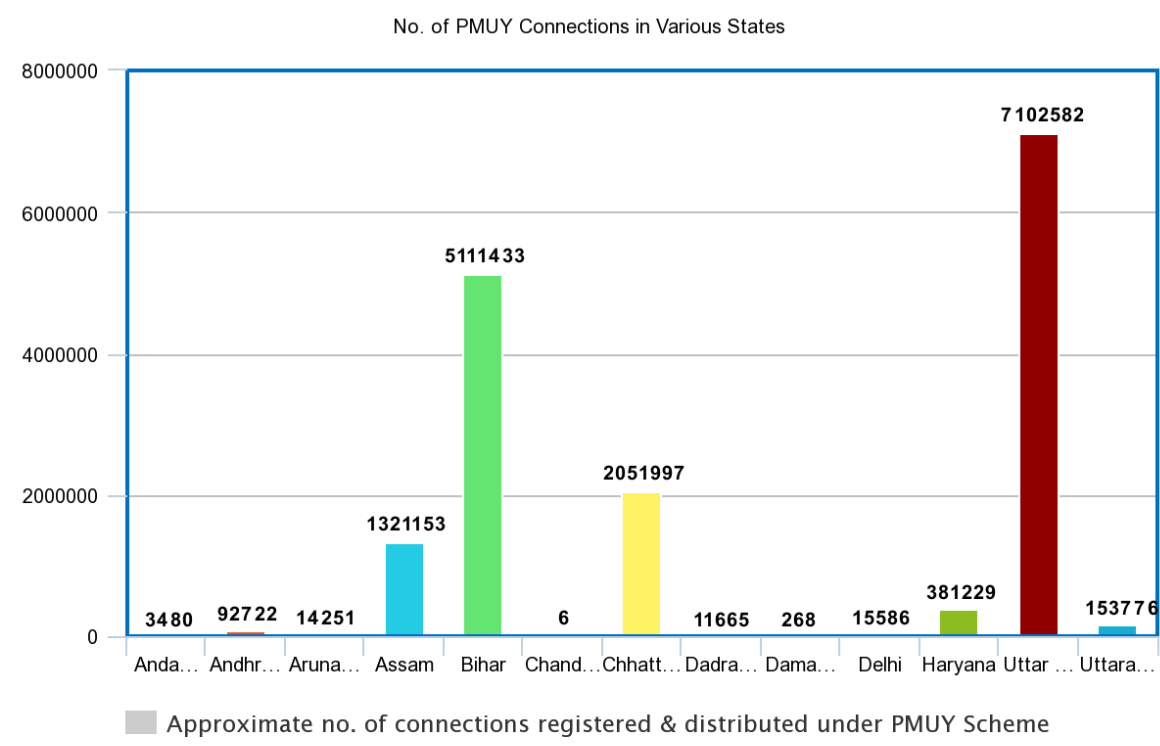

meta-chart.com

Fig IV.I: No. of PMUY Connections in several states

We have considered some data which consist of the no. of connections in various states after the launch of the PMUY. The above bar graph is representing the data of 13 states. Here, one can see that the state which has provided the maximum no. of Pradhan Mantri Ujjwala Yojana connections is Uttar Pradesh and Bihar is at the second positions. Chandigarh is the least PMUY connection provider whereas Daman Diu is at second last position.

\section{Use of Solid Fuel in India}

The tradition fuel i.e. solid fuels are being used since ages in the world. As per WHO assessment (March 2006 ) 74\% of Indian population were using Solid fuel in their houses. The Indian position on use of solid fuel as compared to other South Asia countries is appended below.

\begin{tabular}{|l|c|}
\hline Region/Country & Percentage \\
\hline South East Asia & 74 \\
\hline Indonesia & 72 \\
\hline Sri-Lanka & 67 \\
\hline Thailand & 72 \\
\hline Bangladesh & 88 \\
\hline India & 74 \\
\hline Myanmar & 95 \\
\hline Nepal & 80 \\
\hline
\end{tabular}

(Source: Percentage of population using solid fuels, by country and WHO region- Multiple Implications for the Millennium Development Goal” in Environment Health Prospective, Volume 114 Number 3 in Mar"2006) 
International Journal of Arts and Humanities

ISSN: 2581-3102

Volume: 04, Issue: 01 "January 2020"

From table it is very clear that India needed a great push to direct households towards use of cleaner fuel. Since the availability of cleaner fuel is still a big challenge for rural poor households and health of women and children are getting affected due to use of unclean fuel, the government is desperate to provide cleaner fuel to poor households the idea of Pradhan Mantri Ujjwala Yojana (PMUY) was evolved.

\section{THE SCHEME- PRADHAN MANTRI UJJWALA YOJANA (PMUY)}

April 20, 2018 was celebrated as the Ujjwala Diwas, where on a single day 15,909 LPG (Liquefied Petroleum Gas) Panchayats3 were organized pan India with an estimated attendance of over 5 million beneficiaries. On this single day around 1.1 million new beneficiaries were enrolled and provided with LPG connection under Pradhan Mantri Ujjwala Yojana4 (PMUY). Senior officials from all Oil Marketing Companies (OMCs) participated in the LPG Panchayats, encouraging both the sustained and safe usage of LPG. The day marked affirmation of the commitment to provide clean fuel to practically every family in India.

\section{The Procedures:}

- The women above 18 years belonging to BPL families not having access to LPG connection may apply for new LPG connection in a prescribed format to LPG distributor. While submitting the application the woman must submit the details like address, Jan Dhan / Bank Account number and Adhar number (Adhar if not available to be coordinated with UAID for issuance of Adhar to BPL household)

- The LPG field officials will match the application against SECC-2011database to ascertain the eligibility under BPL status. After that the name and address will be entered on OMC"s portal to eligible applicants.

- OMCs will take electronically the de-duplication exercise and other major due diligence for issuance of new LPG connection under the scheme.

- OMCs will issue the new free LPG connection to eligible beneficiaries. As the connection charges are borne by the government, the OMCs will provide an option to new consumers under this scheme to opt for if so, desires for EMIs for the cost of cooking stove and 1st refill. The EMIs shall be recovered from the amount due to consumer on account of subsidy on their refill.

- In case any state government or voluntary organization or an individual wish to contribute to the cost of cooking stove and 1st refill, may do so in coordination with OMCs. 
International Journal of Arts and Humanities

ISSN: 2581-3102

Volume: 04, Issue: 01 "January 2020"

- OMCs will also organize the education and awareness campaign or Melas at various locations to release of connection to BPL families. The release of connection shall be done in presence of public personalities or distinguished personalities of the area.

- The scheme will cover BPL families under all form of distributorship and for various sizes of cylinders like $14.2 \mathrm{KGs}$ or 5 KGs.

Working Structure of Scheme: For cooking on LPG fuel the standard LPG equipment like LPG Cylinder and Pressure Regulator along with Rubber pipe and Gas Stove is needed. The LPG distributors from Oil Companies provide the standardized LPG equipment to customers taking LPG Connection on payment towards the cost of the equipment. In the given scheme the Central Government is reimbursing the cost of cylinder and pressure regulator $(1400+200)$ to Oil Company for giving LPG connection to BPL family. The BPL family has also option to buy the low-cost gas stove and refill or opt for EMI for the 1st refill and gas stove. In case of opting for EMI the Oil Company is providing the 1st Refill and low-cost Gas Stove through distributor network. In this case the cost of 1st Refill and low-cost Gas Stove Rs.1620 (i.e. Rs 630+Rs. 990) shall be recovered from the subsidies on LPG payable to the BPL family on subsequent refill. Taking the present subsidy on LPG around Rs. 200 per cylinder refill, it will take 8-9 months to offset the initial cost of gas stove and one free refill through EMI. The other individual or organization can also contribute to this social cause by sponsoring the cost of gas stove and refill in coordination through Oil companies. The Punjab State Government has also sponsored for the cost of Gas stove being given to BPL families in Punjab under the scheme. (Business Standard, 2016).

\section{ADVANTAGES OF UJJWALA SCHEME}

Affordability- Affordability is a big concern for the families to switch from the impure fuels to pure fuels. The village people are not capable of buying the LPG on a higher price. PMUY has provided a great opportunity to give free gas connections to the villagers. The government has released a total budget of 8000 crores over 3 years for this scheme. The money is going to utilized from the savings of the subsidy through "GIVE IT UP" campaign.

Women's Empowerment: The time taken in collecting the waste fuels and cooking on that has been saved to an extent. The women of the families can use their saved time for some leisure activities and other works. The time saved in cooking can be a big plus for their exposure in other activities which can definitely raise the social and economic standard of the country. The most important thing is that the connections are issued in the name of the woman head of the household and the subsidy amount is also credited into the bank account of that woman head. 
International Journal of Arts and Humanities

ISSN: 2581-3102

Volume: 04, Issue: 01 "January 2020"

The way government is shaping the life of woman of BPL families is appreciable. They can now give their decisions in the financial matters of the family also.

Healthy Society- Since we know that the smokes and smog released from the burning of waste materials like cow dung cakes and impure fuels contains dangerous elements and carbon monoxide in major amount. The smoke pollutes the air which can cause respiratory diseases like lung cancer, heart disease, stroke, chronic and obstructive pulmonary diseases. Giving BPL families a better fuel to cook is going to reduce the health issues. The visit to the doctor has also been reduced and this shows that cooking on clean fuel minimized the health issues in many families. A strong nation can only build upon a health society.

Clean \& Safe Environment- Giving a clean environment to the upcoming generation is a crucial aspect for every generation. In the present time, we are overusing the natural resources which may results in the horrible way. We are polluting the air, water and earth with hazardous air. The balance is not the same as it was 100 years before, water bodies like river, ponds and lakes are drying up and many creatures are getting rare to find. The air pollution created by the use of waste fuel for cooking is also contributing to the air pollution apart from the industries. With the use of clean Lpg, the pollution can be reduced. The government has also launched Swatch Bharat Program which is raising awareness for providing clean and pure environment to our country. The launching of PMUY scheme has not only provided a better environment to cook but also provided a clean environment to the people of villages.

\section{SURVEY}

WE HAVE PERFORMED A SURVEY ON 500 PEOPLE IN A SMALl VILlAGE IN UTTAR PRADESH, WE ASKED SOME QUESTIONS ON SOCIAL AND ECONOMICAL ASPECT OF PRADHAN MANTRI UJJWALA YOJANA. THE SUMMARY OF THE SURVEY IS AS FOLLOWS-

We came to know that more than 50\% woman cook for 6 people or more than 6 people of their family. PMUY has made things easier for the woman as it has now become the main source of fuel in most of the house. Agriculture waste or cow dung cakes were the main source of fuel before the introduction of PMUY in nearly almost every house of the village. The scheme proved to be a masterstroke as it also reduces the overall time to cook food. It used to take more than 2 hours for cooking in $60 \%$ of the houses whereas on LPG it takes less than 2 hours. When villagers asked about the easiness in cooking food due to this scheme, we got to know that more than 350 villagers were happy enough to accept the fact that it has now become easy as compared to before. 
PMUY also affected the health of the poor people as the visit to doctors due to various reasons has now decreased. No doubt cooking in clean and pure environment provides better health conditions and more than 450 people accepted it in this survey. The people of villages who comes under PMUY feels empowered with gas connections. PMUY has provided a muchneeded push to Indian economy and social life of the people. The refilling time of an LPG cylinder is very frequent in most of the houses. When asked about the money savings under this scheme, they responded that they normally save less than Rs 1000. The Scheme has brought some noticeable changes in the expenditure on health also. The survey gave us an idea that the launching of PMUY was never a fluke. It is a masterstroke for the development of the country.

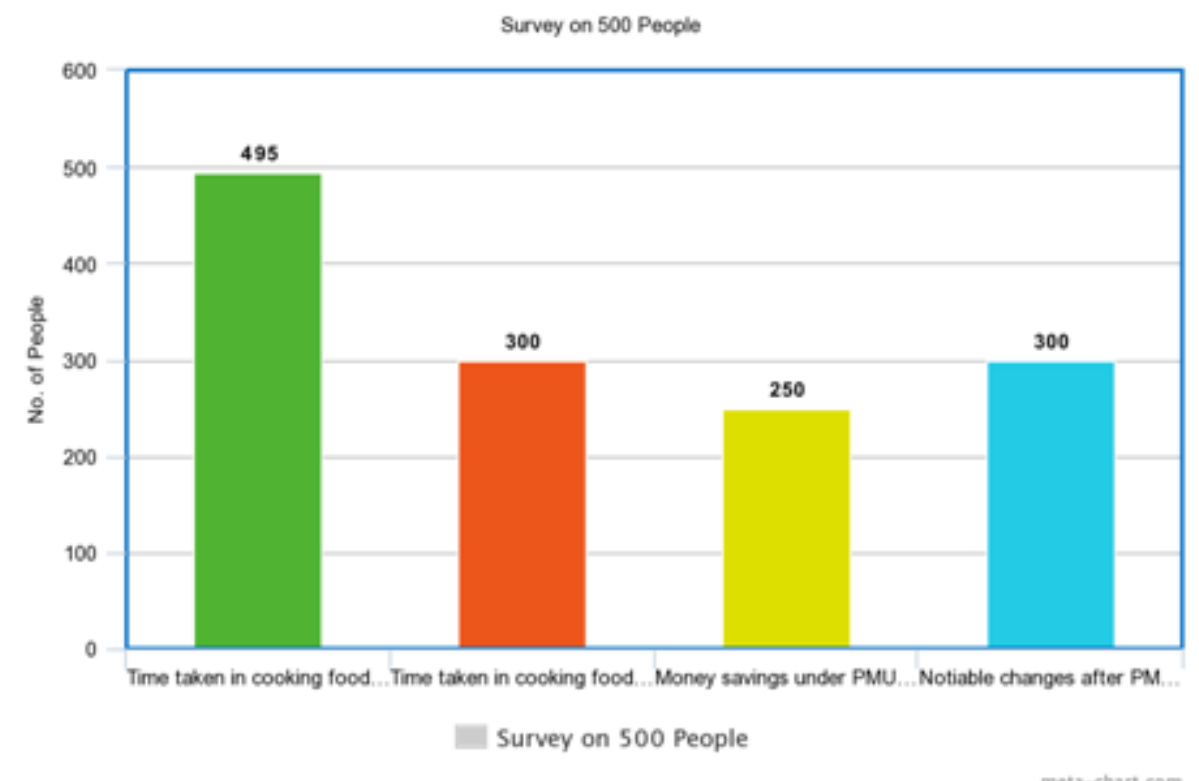

\section{CONCLUSION}

The PMUY has provided a big boost to the social and economical condition of the country. People who belongs to the specific category are now having the clean fuel to cook food. Expenditure, health, time and many more parameters are there on which we can easily conclude that PMUY has developed the lives of villagers in many ways. By launching this scheme government has taken a step closer to the development of the country.

\section{REFERENCES}

[1] Dr. Mamta Sharma Pareek (2018). Analysis of Pradhanmantri Ujjwala Yojana. IJETSR www.ijetsr.com volume 5, issue2. ISSN 2394-3386.

[2] Indoor air pollution caused 1,24,000 premature deaths in India, as per a 2015 st udy by Lancet. 
[3] Sameer Kumar Barua and Sobhesh Kumar Aggarwalla(2018). Lighting up Lives through cooking Gas and transforming society. W.P No. 2018/12/05

[4] Ashwani Dabadge, Ashok Sreenivas, Ann Josey, Prayas(Energy Group) 2018. Pradhan Mantri Ujjwala Yojana: What we need to Know.

[5] N Ahmad, Shalaghya Sharma and Dr. Anjani Kumar Singh (Associate Professor), Amity Business School, Noida. Pradhan Mantri Ujjwala Yojana(PMUY) Step towards social inclusion in India. International Journal of Trend in Research and Development, Volume 5(1), ISSN: 2394-9333

[6] WHO. (2006, March). Assessing Household Solid Fuel Use. Environment Health Prospectives.

[7] Wikipidea- Pradhan Mantri Ujjwala Yojana.

[8] www.pib.gov.in/newsite/printrelease.aspx for Census 2011 data. 